\title{
TIPICIDAD DEL INCESTO EN LA UNIÓN MARITAL DE HECHO
}

\author{
Typicality of Incest in Common-law Marriages
}

Tipicidade do incesto na união marital de fato

Yor Alexander Casas Villamizar (Colombia) Institución Universitaria Politécnico

$$
\text { Grancolombiano }
$$

yorcasas80@hotmail.com

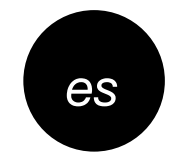

\section{RESUMEN}

El presente artículo expone cómo en Colombia la Ley 54 de 1990 definió la unión marital de hecho. Jurídicamente, la unión marital de hecho es una forma para constituir una familia por vínculos naturales, plasmada en el Estatuto Superior, el cual consagra esta unión como núcleo fundamental de la sociedad, con lo que adquiere calidad integrante en el Estado social de derecho, y obliga al Estado y a la sociedad a su protección integral a través del derecho penal como bien jurídico. El incesto, como realización del acceso carnal $\mathrm{u}$ otro acto sexual con un ascendiente, descendiente, adoptante o adoptivo o con un hermano o hermana, desestabiliza y pone en peligro la institución familiar, y en ello la unión marital de hecho compuesta por parientes endogámicos es una conducta punible y no una sociedad patrimonial.

PALABRAS CLAVE: incesto, vínculo natural, familia, bien jurídico, derecho absoluto, conducta típica.

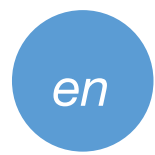

ABSTRACT

This article shows the way Law 54 of 1990 defined common-law marriage in Colombia. Legally, common-law marriage is a way to constitute a family through natural ties. This family is expressed in the Superior Statute, which establishes this union as the essential core of the society, acquiring integral quality within the social state of law and forcing the State and the society to protect it as a legal right by means of the Criminal Law. Incest -understood as carnal knowledge or other sexual act with a predecessor, descendant, adoptive parent, or sibling- destabilizes and imperils the family institution. Common-law marriages composed by incestuous relatives are a punishable behavior and not a marital estate.
KEYWORDS: incest, natural tie, family, legal right, absolute right, typical behavior.

\section{por}

\section{RESUMO}

O presente artigo expõe como na Colômbia a Lei 54 de 1990 definiu a união marital de fato. Juridicamente, a união marital de fato é uma forma para constituir uma família por vínculos naturais, plasmada no Estatuto Superior, o qual consagra esta união como núcleo fundamental da sociedade, com o que adquire qualidade integrante no Estado social de direito, e obriga ao Estado e à sociedade a sua proteção integral através do direito penal como bem jurídico. O incesto, como realização do acesso carnal u outro ato sexual com um ascendente, descendente, adoptante ou adoptivo, ou com um irmão ou irmã, desestabiliza e põe em perigo a instituição familiar, e em isto a união marital de fato composta por parentes endógamos é uma conduta punível e não uma sociedade patrimonial.
PalAVRAS CHAVE: incesto, vínculo natural, família, bem jurídico, direito absoluto, conduta típica.

PARA CITAR este ARTíCULO/TO CITE THIS ARTICLE/PARA CITAR ESTE ARTIGO: 


\section{INTRODUCCIÓN}

Al instituirse por el constituyente la familia como núcleo fundamental de la sociedad, la institución de la familia adquirió, en un principio constitucional, la calidad de bien jurídico, delimitando en ello el espacio de interpretación jurídica en sentido explícito a la finalidad de la norma transcrita en el ordenamiento superior. Por ende, la responsabilidad directa y absoluta de su protección recae en el Estado.

Dichos principios plasmados en los primeros artículos del Estatuto Superior adquirieron a lo largo del texto superior una fuerza vinculante con los fines del Estado, desarrollando en ellos las alternativas de constitución del vínculo familiar, el cual fue instituido en libertad y voluntad de constitución por vínculos naturales o jurídicos, lo que representa un catálogo axiológico del sentido de la norma, la cual imparte un valor constitucional.

Cuando se habla de la predominación del interés general sobre el particular, la fuerza y razón de las decisiones legislativas adquieren un sentido de regulación con las relaciones interpersonales y la moralidad pública. En ello el derecho como instrumento de control social regula la conducta humana en relación con la moralidad pública, valorando éticamente la participación del sujeto en el orden político, lo que, en un principio legal, se consideraría imparcial para la comunidad y el individuo que la conforma.

Por todo lo anterior, la penalización de una conducta constituye un acto jurídico en el cual el legislador establece una norma en la que materializa el principio de moralidad colectiva que el constituyente fijó en el Estatuto Superior, en el cual consideró la institución familiar como un bien jurídico de interés general que merece protección.

\section{UNIÓN MARITAL DE HECHO EN COLOMBIA}

En Colombia, con la Ley 54 de 1990, se ha definido para todos los efectos civiles la unión marital de hecho como la formada entre un hombre y una mujer que, sin estar casados, forman una comunidad de vida permanente y singular (art. 1), hecho que trae como consecuencia el nacimiento a la vida jurídica de la calidad de compañero permanente.
De lo anterior, puede definirse jurídicamente que la unión marital de hecho es una forma para constituir una familia, en la cual un hombre y una mujer sin vínculo jurídico alguno se unen para vivir juntos de una forma estable en comunidad de lecho, techo y mesa. Precisando que "la pareja homosexual que cumpla con las condiciones previstas en la ley para las uniones maritales de hecho, esto es la comunidad de vida permanente y singular, también pueden constituir una familia" (Corte Constitucional, 2007).

Sin embargo, la definición jurídica plasmada en la ley anterior no fue el inicio en nuestro ordenamiento jurídico de la unión por convivencia more uxorio, y ello se aprecia con el reconocimiento de la familia natural plasmado en el artículo 329 del Código Civil de 1873, donde se tenía como concubina de un hombre a la mujer que vivía públicamente con él, como si fueran casados, siempre que uno u otro fueran solteros o viudos. Situación que en su momento abrió la puerta a la definición del concubinato para entender en ello el vínculo natural de la familia, lo cual permitió, a su vez, la evolución jurídica de la unión marital de hecho.

Como resultado, y posteriormente a la Ley 54 de 1990, el artículo 42 de la Constitución Política de Colombia de 1991 plasmó en nuestro ordenamiento jurídico superior la figura de la unión marital de hecho, precisando que la familia se constituye por vínculos naturales o jurídicos, por la decisión libre de un hombre y una mujer de contraer matrimonio o por la voluntad responsable de conformarla, con lo cual se consagró a la familia como núcleo fundamental de la sociedad.

Ante el vacío del concepto general de la unión marital de hecho, en el ordenamiento jurídico colombiano este solo es apreciado a cabalidad en los análisis jurisprudenciales emitidos por la Corte Constitucional, en los cuales la unión marital de hecho corresponde a una de las formas legítimas de constituir la familia, la que no se crea solo a causa del matrimonio, por lo que la unión libre de un hombre y una mujer, aunque no tengan entre sí un vínculo contractual formal, son objeto de protección del Estado y de la sociedad, pues de esta unión se da origen a la institución familiar (Corte Constitucional, 1996b).

Con esa finalidad, la familia formada de vínculos naturales surge de la unión entre un hombre y una mujer 
que sin un vínculo jurídico alguno, o vínculo matrimonial alguno, se comportan ante la sociedad como un matrimonio, y aceptan los elementos y las obligaciones que surgen entre ambos vínculos familiares (Valencia y Ortiz, 2004). Para tal efecto, la jurisprudencia como fuente auxiliar de interpretación, definió a la familia como

aquella comunidad de personas emparentadas entre sí por vínculos naturales o jurídicos, que funda su existencia en el amor, el respeto y la solidaridad, caracterizada por la unidad de vida o de destino que liga íntimamente a sus miembros o integrantes más próximos (Corte Constitucional, 2003, 2005).

Al fijar el Estatuto Superior a la familia como núcleo fundamental de la sociedad, esta adquiere la calidad de parte integrante del Estado social de derecho, y obliga al Estado y a la sociedad el deber de garantizar la protección integral de la familia sin importar el vínculo por el cual se constituye, con lo cual desarrolla la estructura de un sistema garante de la institución familiar, para tutelar este bien jurídico constitucional, que es considerado por la Corte Constitucional

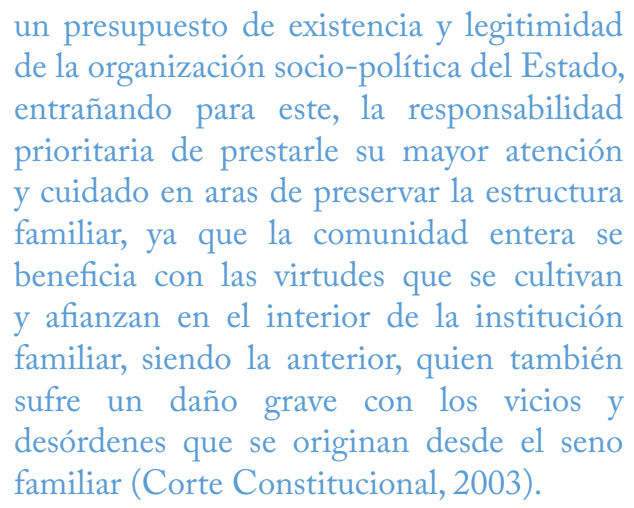

Cuando el constituyente fijó las formas en las cuales se forma la familia, se estructuró el vínculo del matrimonio y el de la unión marital de hecho, con lo cual marcó una diferencia jurídica constituida por el consentimiento, es decir, con el vínculo jurídico para constituir una familia nacen las obligaciones recíprocas, las cuales son exigibles por cada uno de los cónyuges respecto del otro, y terminan solo por la disolución del matrimonio con el divorcio, la muerte o por su declaración de nulidad.

Por ello, la Corte Constitucional sostiene que el matrimonio es la unión de hecho o la cohabitación entre los cónyuges, quienes, al estar casados, son personas jurídicamente vinculadas, mientras que la unión libre es producida por el solo hecho de la convivencia, donde los compañeros son libres en el plano de la vida en común, que determinan en nombre propio la continuidad de su unión o de guardar fidelidad a su pareja (Corte Constitucional, 2000b).

A este respecto, el consentimiento del vínculo jurídico es lo que resulta esencial en el matrimonio; por tanto, sin el consentimiento no existiría vínculo jurídico, tal como lo emana el mandato constitucional a través de la ley civil, en la cual el contrato del matrimonio se constituye y perfecciona por el libre y mutuo consentimiento de los contrayentes ${ }^{1}$, por lo cual se deduce que un vínculo jurídico entre compañeros permanentes, a diferencia del matrimonio, solo se origina y perfecciona por el hecho de la convivencia singular y permanente sin obligaciones recíprocas (Corte Constitucional, 2010).

En torno a este tema, el artículo 42 del Estatuto Superior plasma las palabras claves en las cuales se ligan directamente los elementos de la unión marital de hecho: la decisión libre, la voluntad responsable y la intimidad. Dichos elementos permiten extraer la hermenéutica que el constituyente previó para constituir el vínculo de la familia de forma natural, encaminándolo a los requisitos de su existencia.

Al hablar jurídicamente de la unión marital de hecho, la Ley 54 de 1990 no estableció los requisitos esenciales para formar su existencia; sin embargo, sí los refirió en el momento de presumir la existencia de la sociedad patrimonial de hecho, razón por la cual elementos esenciales como la capacidad y el consentimiento no serían requisitos para formar la unión marital de hecho. Como consecuencia, y tal como se ha mencionado, el inciso 9 del artículo 42 de la Carta Política determina que las formas del matrimonio, es decir, del vínculo jurídico, como la capacidad para contraerlo, los deberes y derechos de los cónyuges, su separación y la disolución del vínculo, se rigen por la ley civil sin prever específicamente lo mismo con el vínculo natural o unión marital de hecho (Corte Constitucional, 2000b).

I Panorama I pp. 81-89 I Volumen 8 | Número 15

1 Código Civil, artículo 115. El contrato de matrimonio se constituye y perfecciona por el libre y mutuo consentimiento de los contrayentes, expresado ante el funcionario competente, en la forma y con solemnidades y requisitos establecidos en este Código, y no producirá efectos civiles y políticos, si en su celebración se contraviniere a tales formas, solemnidades $\mathrm{y}$ requisitos. 
$\mathrm{Al}$ referir lo anterior, la Ley 54 de 1990, aunque define la unión marital de hecho como la forma de constituir una familia, no precisa impedimento alguno para su formación. Esta insuficiencia de la regulación a la luz del ordenamiento superior origina un vacío jurídico que se subsana con el simple consentimiento, sea tácito, sea expreso. En tal efecto, aparentemente impedimentos como la edad, el vínculo anterior vigente, el crimen del cónyuge, la discapacidad mental absoluta o relativa y el parentesco por consanguinidad, afinidad o civil no son requisitos para la constitución y formación de la unión marital de hecho en Colombia.

Al configurarse esta omisión legislativa relativa ${ }^{2}$, aunque el legislador no hubiera previsto en el ordenamiento jurídico los impedimentos anteriores, no significa que estos no dejan de existir, ser previsibles y exigibles en la unión marital de hecho cuando esta se materializa y es contraria al orden público, por afectar la institución familiar, la cual, como se mencionó, es considerada por el Estatuto Superior como institución básica de la sociedad y, por tanto, un bien jurídico que tutelar por el Estado.

\section{PROTECCIÓN DE LA FAMILIA COMO BIEN JURÍDICO}

Dentro del derecho penal, el bien jurídico de la familia como parte integral del ius punendi, al ser consagrado en el Estatuto Superior, reviste de una importante protección en consideración de ser la institución básica de la sociedad; por tanto, su existencia y conservación son una prioridad del Estado, el cual debe garantizar los principios, derechos y deberes en torno a la vida, la honra y la libertad del núcleo familiar en primacía del reconocimiento de los derechos inalienables del sujeto que integra el núcleo familiar.

Dentro de ese marco de protección, la institución familiar es un bien jurídico tutelado en la Declaración Universal de los Derechos Humanos, donde se fija, como un elemento natural y fundamental de la sociedad, lo que obliga a cualquier Estado a su total y garante protección, contemplación jurídica que adquiere, además, integración en nuestra legislación interna, al ser parte

2 Véase Corte Constitucional (2009): "Las omisiones relativas aluden a aquellos casos en los que sí existe un desarrollo legislativo vigente, pero aquél debe considerarse imperfecto por excluir de manera implícita un ingrediente normativo concreto que en razón a la existencia de un deber constitucional específico, debería haberse contemplado al desarrollar normativamente esa materia. integrante del Estatuto Superior con el bloque de constitucionalidad.

Las afirmaciones anteriores refieren en la ultima ratio un tipo penal donde se prohíbe la libertad social entre dos sujetos en aspectos objetivos y subjetivos, las cuales definen de manera inequívoca, expresa y clara las características básicas del tipo penal, el cual, en un supuesto de hecho con una consecuencia jurídica, contiene la protección al bien jurídico tutelado. En consecuencia, como ha sido manifestado por la doctrina penal, la configuración de un tipo penal es la protección al bien jurídico considerado como "circunstancias dadas o finalidades que son útiles para el individuo y su libre desarrollo en el marco de un sistema social global estructurado sobre la base de esa concepción de los fines, o para el funcionamiento propio del sistema" (Roxín, 1997, p. 56).

Ante la protección de los bienes jurídicos por el estatuto penal, la jurisprudencia de la Corte Suprema de Justicia, Sala de Casación Penal, ha manifestado que dentro de los principios que se reglamentan en el sistema penal consagrado en nuestro ordenamiento jurídico, además de configurar su naturaleza y fijar las características fundamentales que permitan su aplicación y ejecución, la exclusiva protección a los bienes jurídicos como principio del concepto dogmático que se fija en la ley es un contexto político y social del modelo del Estado social y democrático de derecho, que ampara las condiciones de vida social, en la medida en que se afecta la convivencia pacífica de los individuos, siendo referida la importancia fundamental que pondera el legislador como garantía del interés público (Corte Suprema de Justicia, 2006).

Lo expuesto ha permitido la evolución jurisprudencial en torno a la tipicidad y fijación de penas, en el entendido de que la ley penal es una restricción al libre desarrollo de los derechos fundamentales, pero, a su vez, el único mecanismo idóneo de protección de estos al ser parte integrante del fin constitucional, es decir que únicamente pueden ser de tipo penal las conductas que afecten un bien jurídico con relevancia constitucional (Corte Constitucional, 2011a).

Con esa finalidad, la potestad punitiva del Estado, que se manifiesta a través de su legislador, reviste unos límites correlativos a los principios de razonabilidad, necesidad, proporcionalidad y legalidad, para ser aplicados tanto en la conducta descrita por el legislador como en 
su sanción. Por consiguiente, con la tipicidad del bien jurídico tutelado, se desarrolla el principio del nullum crimen, nulla poena sine lege (Corte Constitucional, 2012a).

\section{EL INCESTO EN LA LEGISLACIÓN PENAL COLOMBIANA}

Para la legislación penal colombiana, el incesto es la realización del acceso carnal u otro acto sexual con un ascendiente, descendiente, adoptante o adoptivo o con un hermano o hermana ${ }^{3}$, con lo cual este se entiende como la prohibición de relaciones sexuales o cualquier otro acto sexual entre individuos de ascendencia común o parentesco endogámico. No obstante, más allá de la definición jurídica del tipo penal, el incesto es una conducta no autónoma que quiebra la estructura familiar, altera los vínculos de pareja y distorsiona el sistema de relaciones afectivas y sexuales entre los miembros de una institución familiar (Corte Constitucional, 1998).

Con respecto al incesto, algunos estudios antropológicos desarrollados para entender su estructura han coincidido en señalar que la existencia de su prohibición define la tesis hacia el horror universal de esta conducta humana, ya que en muchas sociedades no tienen castigos contra este delito familiar, en unas lo practican y en otras prevalece la absoluta indiferencia hacia este (Fox, 1985). Por lo cual se infiere que la falta de tutela de este tipo penal permite al sujeto activo el desbordamiento del poder masculino, la atracción erótica de la hija hacia el padre, la intrascendencia de la moral religiosa en la ética familiar, la subordinación de género, la alteración de pareja y el vínculo filial y la incapacidad de justicia por el Estado y la sociedad para proteger la institución familiar (Corte Constitucional, 1998).

Con esa referencia, la adecuación del tipo penal del incesto al orden jurídico se desprende de los mandatos constitucionales como previsión de atender el interés público, destacado el aspecto moral en el que pretende operar el ordenamiento jurídico. Como resultado, para el sistema penal colombiano, la familia es un bien jurídico que debe tutelarse y, en consecuencia, la Ley 95 de 1936, el Decreto Ley 100 de 1980 y la Ley 599 de 2000, antiguo y actual ordenamiento jurídico penal, han

3 Código Penal, Ley 599 de 2000, artículo 237. “Incesto. El que realice acceso carnal u otro acto sexual con un ascendiente, descendiente, adoptante o adoptivo, o con un hermano o hermana, incurrirá en prisión de uno (1) a cuatro (4) años". establecido el tipo penal del incesto como protección al bien jurídico de la familia y la moralidad social.

En este delito, para la realización de la conducta típica, la disposición penal tiene como fin la restricción del libre desarrollo de la personalidad, sin tener como única fundamentación el principio de moralidad pública; por lo anterior, la práctica del incesto está asociada a una cadena de daños que se acentúan sobre la sociedad y los individuos, lo que confirma que la sociedad y el Estado son afectados por esta conducta sexual, y por consiguiente sus regulaciones, en principio, no pueden entenderse como injerencias abusivas en un campo propio del sujeto autónomo y de su vida privada, en busca de mantener el seno familiar sin detrimento a la dignidad de las personas. En tales condiciones, el legislador, en atribución conferida por el Estatuto Superior, instituyó en la ley penal las reglas necesarias para preservar el orden público y el interés general (Corte Constitucional, 1998).

Al hablar del incesto, se difiere que no es un delito tipo autónomo, es decir, su conducta típica en general no se manifiesta sola, y por ello se asocia a otros tipos penales en un concurso de conductas punibles, en las que el tipo penal del acceso carnal violento es el predominante para inferir el concurso de tipo en el incesto. En efecto, el tipo penal del incesto "es la característica resultante de configurar el actuar humano con las prohibiciones o mandatos consignados por el legislador en el texto legal" (Velázquez, 2009, p. 550). Hecho jurídico que obliga al juzgador a realizar un juicio de tipicidad para valorar si la conducta coincide o no con la descripción típica consignada en el texto legal (Velázquez, 2009).

Partiendo de los presupuestos anteriores, la doctrina, muy aparte de los postulados jurisprudenciales, es la fuente del derecho que ha trabajado, en general, la estructura del tipo penal en el incesto, que ante su verbo rector de realizar acceso carnal o acto sexual se define como un delito pluriofensivo, dado que con su tipo penal se buscan proteger dos bienes jurídicos: 1) la familia y 2) la libertad y formación sexuales, por lo cual el sujeto activo es considerado monosubjetivo y cualificado a causa del parentesco (Ferro, 2011, p. 561). Es decir, el autor de la conducta penal necesita cumplir con ciertas características determinadas en ley para encajar con el tipo penal, en las cuales el sujeto activo cualificado tendría siempre la calidad de familiar por

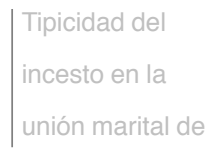


consanguinidad en línea ascendiente o descendente sin importar el grado, colateral consanguíneo en segundo grado o familiar en primero civil. Por tal efecto, el sujeto pasivo queda igualmente cualificado a quien tenga la calidad de familiar por consanguinidad en línea ascendiente o descendente sin importar el grado, colateral consanguíneo en segundo grado o familiar en primero civil del sujeto activo que tenga el dominio de hecho de la acción típica.

Como seguimiento a esta conducta penal, algunos doctrinantes han planteado que en el incesto el sujeto activo y pasivo son las mismas personas, dado que el tipo penal no exige que sea sin consentimiento. Es decir, si hermano y hermana o parientes endogámicos emancipados quieren estar juntos, se tipifica el incesto. Pero si el hermano u otro familiar en consanguinidad o parentesco cualificado por el tipo penal obliga a la hermana o pariente o actúa sin su consentimiento, lo que se presenta es un acceso carnal violento o, en un caso determinado, un acceso o actos abusivos.

A las conclusiones derivadas, como se resaltó, el tipo penal del incesto no exige que sea sin consentimiento o que medie la voluntad, lo que sería en la conducta típica un ingrediente subjetivo, al señalar una específica finalidad de guía para el sujeto activo de la conducta y su realización. Es decir, sin la finalidad convertida en consentimiento o voluntad, la acción se adecuaría a otro tipo penal.

Sin embargo, sin afectar la tesis anterior, el ordenamiento penal ha consagrado los tipos penales abiertos, en los cuales la ausencia de precisión de la conducta típica demuestra que, en determinadas circunstancias, el legislador no plasmó en el tipo penal la descripción perfecta de la conducta, en especial cuando se tutela el bien jurídico de la familia (Corte Constitucional, 2011a, 2012b).

En cuanto al objeto jurídico, es indiscutible negar que sea la familia el bien jurídico que se protege en este tipo penal. Como se ha referido, la familia es un bien jurídico plasmado dentro del mandato constitucional, y en ello se fija como piedra angular de la sociedad; por ende, el Estado es el que fija su inmediata protección. Dentro de este marco, en el incesto el objeto material es la persona en quien se realiza la conducta, persona que 86 puede mediar su consentimiento para la ejecución de la conducta punible, lo que origina un tipo penal bilateral donde el sujeto activo puede ser también el sujeto pasivo, es decir, si en el incesto no media el consentimiento inicialmente se hablaría de otro tipo penal: el acceso carnal violento.

En este sentido, y finalizando con los elementos del tipo penal en el incesto, encontramos, en la norma penal como antesala al verbo rector de realizar acceso carnal o acto sexual, un ingrediente normativo del tipo, donde hallamos, al remitirnos al estatuto punitivo, que se entiende por acceso carnal la penetración del miembro viril por vía anal, vaginal u oral, así como la penetración vaginal o anal de cualquier otra parte del cuerpo humano u otro objeto (Código Penal, art. 212), con lo cual se infiere, en principio de analogía, que un acto sexual es aquel donde interviene la penetración al sujeto pasivo, y en conclusión que el acto sexual y el acceso carnal son un ingrediente normativo en el tipo penal del incesto.

En este sentido, en este delito también se observa como ingrediente normativo la cualificación del sujeto activo o pasivo, al ser delimitados estos a un ascendiente, descendiente, adoptante o adoptivo. A este respecto, al remitirnos a la normativa civil, su estatuto define que, cuando en la línea recta se cuenta bajando del tronco a los otros miembros, se llama descendiente, por ejemplo: padre, hijo, nieto, biznieto, tataranieto, etc.; y cuando se cuenta subiendo de uno de los miembros al tronco, se llama ascendiente, por ejemplo: hijo, padre, abuelo, bisabuelo, tatarabuelo, etc. (Código Civil, art. 43). Igualmente, en el mismo estatuto, se define el parentesco civil como aquel resultado de la adopción mediante la cual la ley estima que el adoptante, su mujer y el adoptivo se encuentran entre sí, respectivamente, en las relaciones de padre, de madre y de hijo (Código Civil, art. 50).

\section{EL INCESTO Y SU TIPICIDAD EN LA UNIÓN MARITAL DE HECHO}

Una vez se ha entendido la figura jurídica de la unión marital de hecho y del tipo penal del incesto, el problema jurídico, después de analizar cómo se puede constituir una familia especialmente por el vínculo natural, es definir si la tipicidad del incesto en la unión marital de hecho es una limitación justificada para proteger el bien jurídico de la familia. Entendiendo que, aunque exista el consentimiento y un interés particular del 
sujeto inmerso en su formación, el derecho fundamental del libre desarrollo de la personalidad, la intimidad y demás hechos inherentes al sujeto de derecho y del núcleo familiar no son absolutos ante el Estado y la sociedad.

Atendiendo a estas consideraciones, la Constitución Política de Colombia, en el artículo 42 en el inciso 4, estableció por el constituyente en el marco jurídico superior que la honra, la dignidad y la intimidad de la familia son inviolables. Pero, al analizar sistemáticamente el articulado constitucional, encontramos en el mismo artículo, en el inciso 6, el asentamiento jurídico de protección de la institución familiar, donde se fija que cualquier forma de violencia en la familia se considera destructiva de su armonía y unidad, y será sancionada conforme con la ley.

De lo anterior se colige que el constituyente, al plasmar el bien jurídico de la familia en el Estatuto Superior, buscó el asentamiento de su protección jurídica ante vulneraciones por factores externos e internos. Es decir, los principios plasmados en la Carta Política buscan dejar en claro que la institución familiar reviste la total y absoluta protección contra lesiones de sujetos ajenos al núcleo familiar, y aquella se extiende a los sujetos que la conforman o son parte de su núcleo. Sujetos que, en el supuesto de hecho, deben respetar los derechos ajenos y no abusar de los propios (Constitución Política, art. 95, numeral 1), para cumplir con uno de los principales fines del Estado: la protección de la institución familiar.

En este caso, fuera de toda discusión jurídica, está señalar que la Constitución Política de Colombia considera a la familia como una institución valiosa y digna de ser protegida, aspecto jurídico que se conforta y se une a las ciencias empíricas que establecen con claridad que los comportamientos incestuosos desestabilizan y ponen en peligro la institución familiar. Por ello, lógicamente se infiere que tales comportamientos deben ser jurídicamente desestimulados por el ordenamiento penal, y en ello el libre desarrollo de la personalidad encuentra un límite razonable en beneficio de la prevalencia del interés general, al ser esta limitación la que se impone en el ordenamiento jurídico, a causa de proteger los derechos de los demás (Corte Constitucional, 1998).

Con esa finalidad, los principios constitucionales descritos imparten en el sistema legal colombiano el carácter absoluto de prohibición del vínculo natural para formar una familia entre parientes que estén en la misma línea de ascendientes, descendientes o hermanos, castigando lo anterior en el ordenamiento punitivo al considerar el acceso carnal o cualquier acto sexual con un ascendiente, descendiente, adoptante o adoptivo, $o$ con un hermano o hermana; conductas contrarias a la existencia, la conservación y el desarrollo de la familia.

En este sentido, la Ley 54 de 1990, sistemáticamente en su estructura, al regular la unión marital de hecho y establecer el régimen patrimonial entre compañeros permanentes, acentúo ideológicamente la prohibición del incesto en la unión marital de hecho, al establecer jurídicamente la presunción de la sociedad patrimonial de hecho cuando exista unión marital de hecho durante un lapso no inferior a dos años entre un hombre y una mujer sin impedimento legal para contraer matrimonio, o cuando exista una unión marital de hecho por un lapso no inferior a dos años e impedimento legal para contraer matrimonio por parte de uno o de ambos compañeros permanentes, siempre y cuando la sociedad o sociedades conyugales anteriores hayan sido disueltas y liquidadas por lo menos un año antes de la fecha en que se inició la unión marital de hecho (Ley 54 de 1990, art. 2).

Sobre la base de las ideas expuestas, las disposiciones en materia civil armonizan los principios constitucionales, para proteger la institución familiar, paralelamente con el Estatuto Penal. En consecuencia, la hermenéutica jurídica de la Ley 54 de 1990 refiere la interpretación tácita de los impedimentos legales para contraer matrimonio o constituir un vínculo jurídico regulado en la ley civil, a fin de ser aplicados en el vínculo natural o unión marital de hecho, aplicando los principios de analogía legis ${ }^{4}$.

En conclusión, cuando parientes endogámicos cualificados por la ley constituyen una familia por vínculos naturales, es decir, mediante la unión marital de hecho, se tipifíca el incesto, y la acción lesiona o pone en peligro el bien jurídico de la familia tutelado por la ley

\footnotetext{
4 Véase Corte Constitucional (1995): "Cuando el juez razona por analogía, aplica la ley a una situación no contemplada explícitamente en ella, pero esencialmente igual, para los efectos de su regulación jurídica, a la que sí lo está. Esta modalidad se conoce en doctrina como analogía legis, y se la contrasta con la analogía juris en la cual, a partir de diversas disposiciones del ordenamiento, se extraen los principios generales que las informan, por una suerte de inducción, y se aplican a casos o situaciones no previstas de modo expreso en una norma determinada.
} 
penal. En este caso, la ley penal, como medio de protección, interviene para tutelar el bien jurídico, y proteger el interés general. Esto implica jurídicamente que, si entre la pareja formada por vínculos naturales existe una relación de parentesco que el ordenamiento considere como incestuosa, esta unión no genera efectos patrimoniales entre los llamados compañeros permanentes y, por consiguiente, no surge entre ellos la unión marital prevista en la Ley 54 de 1990, ni menos aún una sociedad patrimonial, al ser inconcebible que lo que el resto del ordenamiento reprime con reciedumbre fuera protegido por la mencionada ley, lo que generaría incoherencia entre las instituciones legales (Corte Suprema de Justicia, 2005b).

\section{CONCLUSIONES}

En conclusión, a lo largo de este documento, se ha explicado cómo ante el ordenamiento jurídico colombiano se puede constituir una familia, en especial por el vínculo natural, por lo que dicho vínculo requiere para su configuración la voluntad libre y el consentimiento, los cuales se enmarcan en un principio de libertad, que dan nacimiento a la unión marital de hecho. Pero, al nacer a la vida jurídica la institución de la familia a través de este vínculo, nacen con ella las obligaciones y los principios de dignidad, voluntad y moralidad plasmados en el Estatuto Superior, los cuales le dan la calidad de un bien jurídico, al ser la institución básica de la sociedad; por ello, su protección está a cargo directo del Estado y no de sus integrantes.

A pesar de que el legislador y el constituyente no plasmaron en el ordenamiento jurídico los impedimentos de formación de la unión marital de hecho, iguales a los del vínculo jurídico, los impedimentos anteriores plasmados en el Estatuto Civil se encuentran ideológicamente inherentes en la Ley 54 de 1990, la cual regula la unión marital de hecho, así no estén plenamente visibles para la formación de esta unión marital. Por consiguiente, los derechos fundamentales de sus integrantes no son absolutos ante el Estado, y su límite se fija al inicio de los derechos de la sociedad; de ahí inicia la intervención de la ley penal que tutela el bien jurídico de la familia por disposición constitucional.

En pocas palabras, las instituciones jurídicas colombianas, al coincidir en la prohibición de las relaciones incestuosas, aplican un concepto de seguridad jurídica, que repele la lesión al bien jurídico de la familia, hecho que trae como consecuencia jurídica la invalidez de la unión por vínculos naturales y, por ende, para los parientes endogámicos que la conforman no nacerían a la vida jurídica los efectos patrimoniales y personales que trae consigo la unión marital de hecho, tras lo cual se configura una conducta punible y no una sociedad marital.

\section{REFERENCIAS BIBLIOGRÁFICAS}

1. Congreso de la República de Colombia (1936, 24 de abril). Ley 95 de 1936.

2. Congreso de la República de Colombia (1990, 31 de diciembre). Ley 54 de 1990. Diario Oficial, 39615.

3. Congreso de la República de Colombia (1980, 20 de febrero). Decreto Ley 100 de 1980. Diario Oficial, 35.461.

4. Congreso de la República de Colombia (2000, 24 de julio). Ley 599 de 2000. Diario Oficial, 44.097 .

5. Congreso de la República de Colombia (2005, 27 de junio). Ley 979 de 2005. Diario Oficial, 45982 .

6. Corte Constitucional de la República de Colombia (1992, 12 de noviembre). Sentencia C-587. Gaceta de la Corte Constitucional.

7. Corte Constitucional de la República de Colombia (1995, 1 de marzo). Sentencia C-083. Gaceta de la Corte Constitucional.

8. Corte Constitucional de la República de Colombia (1996a, 4 de febrero). Sentencia C-070. Gaceta de la Corte Constitucional.

9. Corte Constitucional de la República de Colombia (1996b, 7 de marzo). Sentencia C-098. Gaceta de la Corte Constitucional.

10. Corte Constitucional de la República de Colombia (1998, 10 de agosto). Sentencia C-404. Gaceta de la Corte Constitucional.

11. Corte Constitucional de la República de Colombia (2000a, 18 de abril de 2012). Sentencia C-289. Gaceta de la Corte Constitucional.

12. Corte Constitucional de la República de Colombia (2000b, 10 de mayo). Sentencia C-533. Gaceta de la Corte Constitucional. 
13. Corte Constitucional de la República de Colombia (2001, 2 de agosto). Sentencia C-814. Gaceta de la Corte Constitucional.

14. Corte Constitucional de la República de Colombia (2002, 30 de abril). Sentencia C-309. Gaceta de la Corte Constitucional.

15. Corte Constitucional de la República de Colombia (2003, 1 de abril). Sentencia C-271. Gaceta de la Corte Constitucional.

16. Corte Constitucional de la República de Colombia (2005, 9 de agosto). Sentencia C-821. Gaceta de la Corte Constitucional.

17. Corte Constitucional de la República de Colombia (2006, 10 de mayo). Sentencia C-355. Gaceta de la Corte Constitucional.

18. Corte Constitucional de la República de Colombia (2007, 7 de febrero). Sentencia C-075. Gaceta de la Corte Constitucional.

19. Corte Constitucional de la República de Colombia (2009, 1 de abril). Sentencia C-314. Gaceta de la Corte Constitucional.

20. Corte Constitucional de la República de Colombia (2010, 9 de agosto). Sentencia C-840. Gaceta de la Corte Constitucional.

21. Corte Constitucional de la República de Colombia (2011a, 23 de mayo). Sentencia C-442. Gaceta de la Corte Constitucional.

22. Corte Constitucional de la República de Colombia (2011b, 26 de julio). Sentencia C-577. Gaceta de la Corte Constitucional.

23. Corte Constitucional de la República de Colombia (2012a, 21 de marzo). Sentencia C-121. Gaceta de la Corte Constitucional.

24. Corte Constitucional de la República de Colombia (2012b, 17 de diciembre). Sentencia C-241. Gaceta de la Corte Constitucional.

25. Corte Suprema de Justicia (2005a, 12 de diciembre). Sentencia 23899.

26. Corte Suprema de Justicia (2005b, 19 de diciembre). Sentencia 7756.

27. Corte Suprema de Justicia (2006, 26 de abril). Sentencia 24612

28. Ferreira, F. (2006). Derecho penal especial. Bogotá: Temis.
29. Ferro, J. (2011). Lecciones de derecho penal: parte general (2..$^{\mathrm{a}}$ ed.). Bogotá: Universidad Externado de Colombia.

30. Fox, R. (1985). Sistemas de parentesco y matrimonio (4. ${ }^{\mathrm{a}}$ ed.). Madrid: Alianza.

31. Gómez, F. (2013). Constitución politica de Colombia anotada (31. ${ }^{\mathrm{a}}$ ed.). Bogotá: Leyer.

32. Hinestrosa, F. (1976). Estudios de derecho de familia. Bogotá: Universidad Externado de Colombia.

33. Legis (2011). Constitución Politica de Colombia (25. a ed.). Bogotá: Legis.

34. Legis (2014a). Código Civil (32. a ed.). Bogotá: Legis.

35. Legis (2014b). Código Penal, Ley 599 de 2000, códigos de Procedimiento Penal, Ley 906 de 2004,

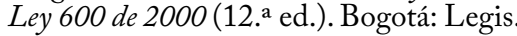

36. Naranjo, F. (2003). Derecho civil, personas y familia (10. ${ }^{\mathrm{a}}$ ed.). Medellín: Librería Jurídica Sánchez.

37. Naranjo, V. (2003). Teoría constitucional e instituciones politicas (9. ${ }^{\mathrm{a}}$ ed.). Bogotá: Temis.

38. Parra, J. (2008). Derecho de familia. Bogotá: Temis.

39. Reyes, A. (1999). Antijuricidad (4. ${ }^{\text {a }}$ ed.). Bogotá: Temis.

40. Roxín, C. (1997). Derecho penal:parte general. Madrid: Civitas.

41. Suárez, R. (1999). Derecho de familia (3. ${ }^{\mathrm{a}}$ ed.). Bogotá: Temis.

42. Tafur, A. (2013). Código Civil anotado. Bogotá: Leyer.

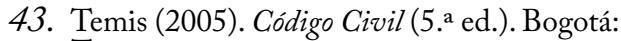
Temis.

44. Valencia Zea, A. y Ortiz, A. (2004). Derecho civil. Bogotá:Temis.

45. Velázquez, F. (2009). Derecho penal (4. ${ }^{\mathrm{a}}$ ed.). Bogotá: Comlibros. 